\title{
An induction period in the formation of the dissipative structures in solutions of anthraquinone
}

\author{
Svetlana G. Karitskaya ${ }^{1}$ * , Sergey Ponomarev ${ }^{2}$ \\ ${ }^{1}$ Department of Mathematics, Ural Federal University, Yekaterinburg, Russia \\ 2 Department of Physics and Technology, Karaganda State University, Karaganda, Kazakhstan
}

\section{A R T I C L E IN F O}

\section{Article history:}

Received 27 January 2017

Received in revised form

9 March 2017

Accepted 10 April 2017

\section{Keywords:}

Luminescence

Anthraquione

Ketyl

Induction period

Oxygen

\begin{abstract}
A B S T R A C T
The purpose of the present work is to characterize the induction period in the kinetics of the formation of luminescent dissipative spatial temporal structures in solutions of anthraquinone. Such structures are formed under ultraviolet illumination in isopropyl alcohol solutions and silicone polymeric films. The structures exhibit three distinctive stages in time, induction, "fast", and "slow". During the induction period, no luminescence is observed, and the "fast" and "slow" stages are characterized by the appearance of bright luminescent products. Although similar luminescent structures have been previously reported in literature, no study has been conducted on the characterization of their induction periods. In our work, the observed luminescence is attributed to ketyl radicals while the formation of the structures requires heat and mass (oxygen and solvent radicals) transfer to and from the reaction zones. The induction period appears to be highly sensitive to the intensity of illumination, oxygen and solvent radicals concentrations.
\end{abstract}

(C) 2017 The Authors. Published by IASE. This is an open access article under the CC BY-NC-ND license (http://creativecommons.org/licenses/by-nc-nd/4.0/).

\section{Introduction}

Self-organization is the wide spread phenomenon occurring in many fields (Haken, 2008). In physics and chemistry, when system is open to energy and matter transfer, it results in the formation of complex dissipative spatial temporal structures (STS). They can be oscillating and repetitive, are characterized by so-called induction period (Cadena et al., 2005), and can appear in numerous forms and shapes such as solutions changing color (nonlinear chemical oscillator by the Belousov-Zhabotinsky reaction) or patterned convection cells (Benard cells) which are developed by heat transfer gradients in the system (Schneider and Sagan, 2005). In 1990s, in the former Soviet Union, there was reported a special type of such STS, fluorescent or luminescent (Vinogradov et al., 1990). These luminescent STS are formed in air-saturated solutions of organic dyes in organic solvents and polymeric films where ultraviolet radiation (UV) initiates the corresponding photochemical reactions accompanied by heat-and-mass transfer in the form

\footnotetext{
* Corresponding Author.

Email Address: sv.karitskaya@rambler.ru (S. G. Karitskaya) https://doi.org/10.21833/ijaas.2017.05.016

2313-626X/C) 2017 The Authors. Published by IASE.

This is an open access article under the CC BY-NC-ND license

(http://creativecommons.org/licenses/by-nc-nd/4.0/)
}

of redistribution of concentration of the reagents and photoreaction products. In particular, we have discovered a very pronounced and brightly luminescent STS in alcohol solutions of anthraquinone (Karitskaya, 2003; Akylbaev et al., 2003). It was shown that the luminescent photoproduct, ketyl radical of anthraquinone, is responsible for the formation of the structures. In addition, the studies concluded that such luminescent STS could find useful applications in modeling chemical reactions in micelles (as nanoscale chemical reactors) and developing remote nonlinear sensors for detection of oxygen and also residual solvents in paints and coatings. In this publication, we describe one of the features of luminescent STS, the induction period, its variables and non-linear character that can be used in sensor applications.

\section{Materials and methods}

The detailed description of the experimental materials and methods are given in (Karitskaya, 2003; Akylbaev et al., 2003). In this section, we would like to present the following technical details needed for the purpose of this paper:

- Anthraquinone was dissolved in isopropyl alcohol and its concentrations varied from $10^{-11}$ to $10^{-3}$ 
mole/l. The solutions were tested in a thick quartz cell with the dimensions $24 \times 11 \times 34 \mathrm{~mm}$ and thin quartz round cells $0.2-1 \mathrm{~mm}$ thick.

- Anthraquinone $\left(10^{-3} \mathrm{~mole} / \mathrm{l}\right)$ was also tested in RTV silicone rubber films with thickness about 25 - 50 microns.

UV $\mathrm{N}_{2}$ laser (337 nm) with $100 \mathrm{~kW}$ pulses, the pulse repetition rates of $100 \mathrm{~Hz}$, and the pulse duration about 10 nanoseconds was used to illuminate the anthraquinone solutions.

\section{Results and discussion}

Fig. 1 presents a photo of a typical STS formed in $3 \cdot 10^{-5}$ mole/l solution of anthraquinone along with the graph showing time modes of the STS formation.

The formation of the STS can be describes as follows.

The time from 0 to $t_{1}$ is the induction period when the UV illumination is on and no visible luminescence is observed. All the UV light is completely absorbed and no luminescence photoproduct is formed. At $t_{1}$, a bright luminescent spot rapidly, in a matter of 1 - 2 seconds, appears and is located on the cell's surface facing the UV light. Afterwards, a second luminescent zone is progressively formed during next a few seconds $\left(t_{2}\right)$. The zone looks like a luminescent cone positioned along the UV laser beam and it stops growing until the time $t_{3}$. In about 60 seconds after the cone is formed, at $t_{3}$, next (third) luminescent zone appears, either in the form of cone or ball-like. The ball luminescent zone is formed at higher $\left(10^{-4} \div 10^{-3}\right.$ mole/l) concentrations. During next 20 - 30 seconds of the illumination either second or third zones begin diffusing towards the upper level of the solution open to the air. Once they disappear from the laser beam, the second and third stages of the formation of the luminescent cones and balls are repeated creating the appearance of oscillating structures.

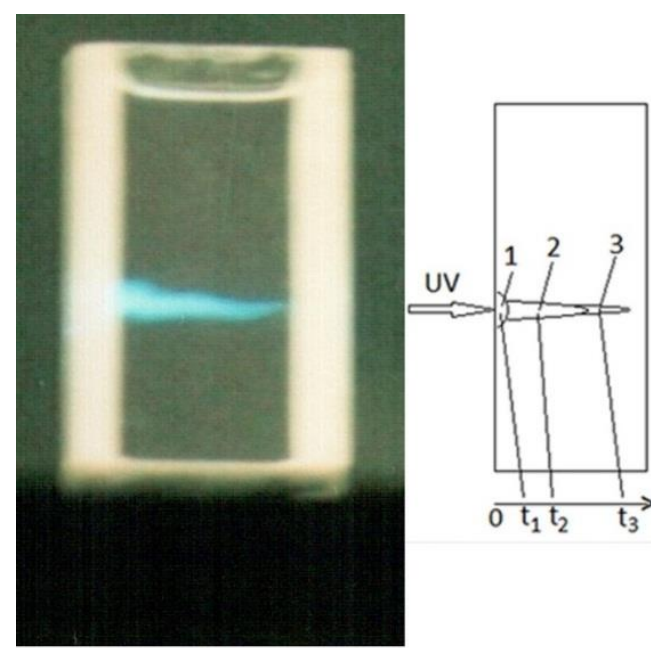

Fig. 1: Typical STS of anthraquinone in isopropyl alcohol solution $\left(3 \cdot 10^{-5}\right.$ mole/l), photograph and time modes of the formation
Fig. 2 shows typical absorbance and luminescence spectra of the anthraquinone solutions. The bright green luminescence is observed at around $490 \mathrm{~nm}$ and it is attributed to the ketyl radical of anthraquinone as it is shown in (Karitskaya, 2003; Akylbaev et al., 2003).

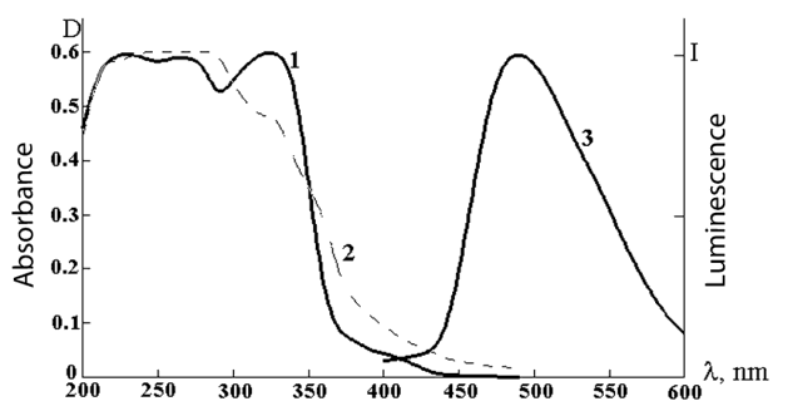

Fig. 2: Absorbance and luminescence spectra of the anthraquinone solution in isopropyl alcohol, $3 \cdot 10^{-5} \mathrm{~mole} / \mathrm{l}$ :

1 - before UV illumination; 2 - after 15 min of UV illumination; 3 - luminescence

The formation of STS, on the other hand, is a macroscopic phenomenon and is determined by concentrations of oxygen and the radicals of isopropyl alcohol and anthraquinone in the zone of the reactions (Eqs. 1-5):

$\mathrm{A}^{3}+\mathrm{RCH}-\mathrm{OH} \rightarrow \mathrm{AH}^{*}+\mathrm{RC}-\mathrm{OH}^{*}$,

$A H^{*}+A H^{*} \rightarrow H A-A H$,

$\mathrm{RC}-\mathrm{OH}^{*}+\mathrm{O}_{2} \rightarrow \mathrm{RCH}_{\backslash_{\mathrm{O}-\mathrm{O}^{\circ}}^{\mathrm{OH}}}^{\mathrm{OH}}$,

$R C H_{\backslash_{O-O}}^{O^{O H}}+A H^{*} \rightarrow R C H_{{ }^{O-O H}}^{O^{O H}}+A^{0}$,

$\mathrm{RCH}_{\backslash_{\mathrm{O}-\mathrm{OH}}}^{\mathrm{OHO}^{\mathrm{O}}} \rightarrow \mathrm{RC}=\mathrm{O}+\mathrm{H}_{2} \mathrm{O}_{2}$,

where, $A^{0}, A^{3}$ are singlet and triplet states of anthraquinone, respectively; $\mathrm{RCH}-\mathrm{OH}$ is isopropyl alcohol molecule; $A H^{*}$ is anthraquinone ketyl radical, $\mathrm{RC}-\mathrm{OH}^{\circ}$ is isopropyl alcohol radical; and $\mathrm{HA}-\mathrm{AH}$ is anthraquinone pinacone. During the induction period $\left(<\mathrm{t}_{1}\right)$, UV illumination leads to the formation of isopropyl alcohol and anthraquinone radicals (1) in the concentrations enough to bind all the oxygen in the reaction zone (3) and stimulate, by that, the reaction (1) in the absence of oxygen. As it is realized, the diffusion of oxygen and its absorption in the reaction zone are stabilized leading to the formation of the first bright luminescent spot at $t_{1}$ and then to the further second and third luminescent zones at $t_{2}$ and $t_{3}$, respectively.

The appearance of the anthraquinone STS in the thin cells is shown in Fig. 3. The induction period was about 60 seconds resulting in the formation of a bright luminescent spot. During next 120 seconds $\left(\mathrm{t}_{2}\right)$ the dot was growing to the middle size luminescent spot with diameter about $7 \mathrm{~mm}$. By the time $t_{2}$, the formation of the spot was slowing down and after $t_{2}$, it began growing again $\left(t_{3}\right)$ to the maximum size about $15 \mathrm{~mm}$ in diameter. The period of time $t_{3}$ was about 240 seconds. In the silicone films, the formation of the STS was very fast and took about 2 seconds. The STS were formed only once. 

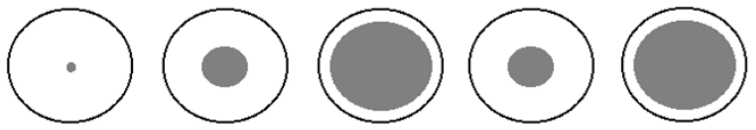

$720 \mathrm{sec}$

Fig. 3: Anthraquinone STS in thin cells of isopropyl alcohol

Fig. 4 presents the representative dependences of the STS luminescence intensities, induction period $t_{1}$ and the times of $t_{2}$ and $t_{3}$ of the formation of the second and third luminescent zones (in relative units and averaged over the test samples in solutions and silicone films) in time. Over time, the luminescent zones formed during the "slow" stage exhibit spatial transformations in time (diffusion, breaks-up, consolidation and formation of "blurred" structures) that result in non-regular oscillations of the total luminescence intensity. These transformations and luminescence intensity oscillations depend of the solution concentrations and distance from the upper level of the solution (or proximity to the source of oxygen, air). The closer to the upper level, the more frequent luminescent oscillations and zone transformations are observed.

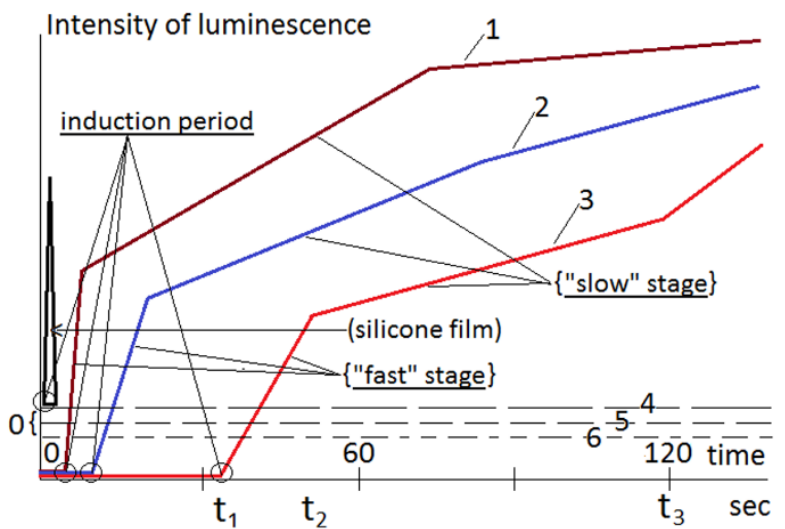

Fig. 4: The averaged dependence of the intensity of the STS luminescence (relative units) on time for various concentrations of anthraquinone: 1, 2, 3, 4, 5 and $6-10^{-3}$, $10^{-4}, 3 \cdot 10^{-5}, 10^{-6}, 10^{-8}$ and $10^{-11}$ mole/l, respectively

\section{Conclusion}

The formation of the anthraquinone STS in isopropyl alcohol solutions and luminescent zones in silicone films are highly sensitive to the presence of oxygen and alcohol molecules.

In both types of the media, the luminescence appears after a certain induction period and is attributed to ketyl radicals.

In polymeric silicone films, the STS are formed very rapidly, in a matter of seconds, the induction period is extremely short, and the reactions take place only once during the laser UV illumination.

Such characteristics of the luminescent STS and zones show a possibility of using them for remote detection of residual alcohol in oxygen permeable coating formulations.

\section{References}

Akylbaev GS, Karitskaya SG, and Kobzev GI (2003). On the mechanism of appearance and development of structures in alcohol solutions of anthraquinone. International Journal of Nonlinear Sciences and Numerical Simulation, 4(2): 179-186.

Cadena A, Pérez N, Agreda J, and Barragán D (2005). Understanding of the induction period of the BelousovZhabotinsky reaction. Journal of the Brazilian Chemical Society, 16(2): 214-219. Available online at: http://www.scielo.br/scielo.php?pid=S0103$50532005000200014 \&$ script=sci_arttext\&tlng=pt

Haken H (2008). Self-organization. Scholarpedia, 3(8): 1401. http://dx.doi.org/10.4249/scholarpedia.1401

Karitskaya SG (2003). Luminescence of structures formed in aqueous alcohol solutions of anthraquinone. Journal of Applied Spectroscopy, 70(2): 265-269.

Schneider ED and Sagan D (2005). Into the cool: Energy flow, thermodynamics, and life. The University of Chicago Press, Illinois, USA.

Vinogradov LZ, Krasheninnikov AA, and Shablya AV (1990). Formation and luminescence of spatial-temporal structures due to occurrence of photochemical reactions in solutions of organic compounds. Optics and Spectroscopy, 68(6): 822823. 